\title{
Intercâmbio Neocorporatista e Inovação Tecnológica: o Caso do Padrão Eucalipto na Aracruz S. A.
}

\author{
José Célio Silveira Andrade \\ Camila Carneiro Dias
}

\section{RESUMO}

Diversos estudos interpretam o dinamismo econômico do complexo agroindustrial de celulose mediante diferentes perspectivas: o progresso tecnológico neoschumpeteriano; a atuação de políticas públicas planejadas; a influência de lobbies de representação de interesses privados etc. Entretanto resta um domínio pouco investigado pelos pesquisadores: aquele onde se desenvolvem as relações Estado-agentes econômicos como uma via expressa de mão dupla, na qual se tecem acordos importantes para a construção de um ambiente político-institucional propício à configuração de novos paradigmas econômico-tecnológicos nas empresas. Tomando como ilustração a análise da emergência e consolidação do padrão eucalipto na Aracruz Celulose S.A, entre 1965-1992, o trabalho argumenta que este processo de inovação tecnológica foi resultado histórico de interações das estratégias tecnológicas empresariais com o ambiente político-institucional, construído a partir de um duplo movimento de interação política das agências governamentais com a auto-organização de interesses privados. Para tal, os autores se utilizam de uma grade analítica construída a partir da articulação entre a abordagem neochumpeteriana de progresso tecnológico e a abordagem institucionalista de intercâmbio político neocorporatista.

Palavras-chaves: complexos agroindustriais; inovação tecnológica; ambiente político-institucional; neocorporatismo; celulose de mercado.

\begin{abstract}
There are several studies related to the explanation of the economic dynamism of Brazilian agroindustrial chain of eucalyptus market-pulp, based on quite different theoretical perspectives: neoschumpeterian technological progress; planned public politics; lobbies of private interests. However, there is still a domain which remains underestimated by researchers: that related to the relationship builded between the State and the economic agents as a process of exchanging interests, where are negotiated important arrangements for the construction of a political-institutional ambience favorable to the shaping of new techno-economic paradigms. Analysing the emergence and establishment of eucaplyptus pattern in Aracruz Celulose S.A., in the period 1965-1992, the authors argue that this process is the historic result of interactions between corporate strategies and its political-institutional milieu, made up as a movement of political orchestration among governamental agencies and self-organized private interests. In doing so, the authors constructed an analytic tool resulting from the articulation of the neoschumpeterian dimension of technological innovation and the neo-institutionalist economical approach, focused on neocorporatist forms of political interchange.
\end{abstract}

Key words: agroindustrial chains; technological innovation; political-institutional ambience; neocorporatism; eucalyptus market-pulp. 


\section{INTRODUÇÃO}

A década passada iniciou-se com sérias preocupações acerca do grau de competitividade internacional da indústria brasileira. Uma exceção era aberta, quando se tratava do complexo agroindustrial de celulose de fibra curta de eucalipto, cuja competitividade é freqüentemente reconhecida em âmbitos empresariais, governamentais e acadêmicos. Este complexo é composto, atualmente, por empresas não integradas completamente, como a Aracruz Celulose S. A., que produzem celulose de mercado, a partir do eucalipto, em plantas com grandes escalas de produção (Gertner et al., 1997). Estudos recentes apresentam diversas abordagens para interpretar o desempenho exitoso do complexo agroindustrial brasileiro de celulose e a sua constituição e dinâmica econômica: (1) uma abordagem que privilegia o progresso técnico por meio da inovação tecnológica; (2) outra que privilegia o papel de um Estado estruturalista, no qual as políticas públicas são resultado exclusivo de uma intenção deliberada e monolítica de planejamento governamental; (3) uma outra que privilegia a posição passiva do Estado pluralista, sujeito à atuação de lobbies de grupos de pressão privados (Soto, 1992).

Observamos que todas essas interpretações, embora contribuam com elementos importantes para a análise da constituição e consolidação do complexo agroindustrial de celulose de eucalipto, são insuficientes para dar conta de todas as suas especificidades. Não se trata de negar a validade dos referenciais teóricos aqui apresentados, porém alertar para os limites de cada um deles, quando tomados separadamente para analisar a configuração do atual padrão de inovação tecnológica do complexo agroindustrial brasileiro de celulose.

Asseverado isso, verifica-se a necessidade de articular os conceitos neoschumpeterianos de competitividade e inovação tecnológica com a dimensão políticoinstitucional da relação Estado-agentes econômicos. A grade que integra as análises neoschumpeteriana e institucionalista foi estruturada como se segue. Primeiro, foram abordados os diferentes enfoques conceituais de complexo agroindustrial e as diferentes perspectivas de análise das inovações tecnológicas incorporadas por esses conceitos. A seguir, foram discutidas as formas convencionais dos complexos lidarem com a questão tecnológica: as abordagens neoclássica e neoschumpeteriana. Para isto, foi traçada a trajetória evolutiva do conceito de competitividade industrial: da clássica formulação ricardiana de vantagem comparativa ao conceito contemporâneo de competitividade dinâmica. Finalmente, articulavam-se as perspectivas neoschumpeteriana e neocorporatista de inova- 
ção tecnológica com o objetivo de interpretar a dinâmica do processo de inovação tecnológica e de construção de vantagens competitivas no interior do complexo agroindustrial de celulose.

$\mathrm{O}$ argumento desenvolvido parte do pressuposto de que o processo de emergência e consolidação do padrão de inovação tecnológica de clonagem do eucalipto, durante o período entre 1965-1992, foi resultado histórico de interações das estratégias tecnológicas empresariais com o ambiente político-institucional. Tal ambiente foi construído a partir de duplo movimento de intercâmbio político neocorporatista, entre as agências governamentais e a auto-organização de interesses privados, para a gestão de políticas públicas específicas referentes à integração floresta-indústria, aumento da economia de escala e apoio institucional ao desenvolvimento científico e tecnológico do padrão eucalipto.

Este trabalho tem por objetivo analisar o processo de emergência e consolidação do padrão de inovação tecnológica de clonagem do eucalipto e a construção de vantagens competitivas pela Aracruz Celulose S.A, durante o período entre 1965-1992, utilizando-se uma grade analítica construída a partir da articulação entre a abordagem neoschumpeteriana de progresso tecnológico e a abordagem institucionalista de intercâmbio político neocorporatista das agências governamentais com as associações de representação de interesses privados. Para coletar as informações necessárias à fundamentação do argumento deste estudo de caso foram analisados dados secundários, extraídos de documentos internos, relatórios e publicações técnico-científicas. Estes foram complementados com dados primários obtidos por meio de pesquisa de campo, do tipo observação nãoparticipante, e entrevistas semi-estruturadas com informantes-chaves da empresa.

\section{Cadeias Produtivas e Complexos Agroindustriais: Enfoques Conceituais}

De acordo com Graziano da Silva (1996), o longo processo de transformação da base técnica da agricultura brasileira, culmina, pois, na sua própria industrialização, caracterizando o processo de passagem do chamado complexo rural para uma dinâmica comandada pelos complexos agroindustriais. A constituição dos complexos agroindustriais brasileiros pode ser localizada nas décadas de 60/70, a partir da integração técnica setorial entre a indústria e as atividades agrícolas e agroflorestais. Desde então, diferentes versões do termo complexo agroindustrial têm sido utilizadas no Brasil, vinculadas a duas abordagens distintas. A primeira refere-se à existência de vários complexos agroindustriais, sendo uma abordagem desenvolvida a partir da evolução do conceito de complexos rurais. A se- 
gunda refere-se ao complexo agroindustrial, enquanto uma unidade macro de análise, inspirada nos conceitos de agribusiness, sistema agroalimentar e filière.

As abordagens relacionadas ao conceito de macrocomplexo (CAI) e aquelas referentes à idéia de múltiplos complexos agroindustriais (CAIs) remetem a diferentes noções do conceito de complexo. A noção de complexos, vinculada à existência de múltiplos CAIs, designa as relações multideterminadas de encadeamento, coordenação ou controle entre os seus vários elementos, membros ou etapas do processo. Tal noção tem origem nas teorias de desenvolvimento econômico dos anos 50, que ressaltavam a importância de realização de investimentos em determinadas atividades estratégicas, no intuito de completar as lacunas da estrutura produtiva industrial, na medida em que estas atividades teriam o poder de induzir o surgimento de outras nos ramos com que estivessem em comunicação.

Por sua vez, a noção de complexo, implícita no conceito de macrocomplexo, nada tem que ver com quaisquer teorias do desenvolvimento ou com a idéia de dinâmica do crescimento, mas relaciona-se a um conjunto de atividades interrelacionadas, agregadas por um ou mais critérios previamente definidos. Essa noção representa um recorte estático, obtido a partir de quaisquer critérios de agregação de atividades afins, característica que, na interpretação de Graziano da Silva (1996), remete imediatamente à noção de agribusiness. As noções de agribusiness, de sistema agroalimentar e de análise de cadeia ou filière agroalimentar, foram utilizadas neste sentido, respectivamente, por Davis e Goldberg (apud Machado Filho et al., 1996) e Malassis (1973). A variável tecnológica recebe tratamento especial nas duas abordagens, porém diferenciado. Enquanto a literatura de cadeias ou filière apresenta uma perspectiva schumpeteriana, o estudo das mudanças tecnológicas, no modelo de agribusiness, é de concepção neoclássica, restringindo-se às inovações induzidas por mudanças nos preços dos fatores.

\section{Competitividade e Inovação Tecnológica: Abordagens Neoclássica e Neoschumpeteriana}

A abordagem neoclássica da vantagem comparativa (Ohlin apud Porter, 1990) apoia-se na idéia de que as nações têm, todas, a mesma tecnologia disponível, mas diferem quanto à disponibilidade dos fatores de produção: os fatores nada mais são do que os insumos básicos necessários à produção e os países ganham vantagem comparativa naquelas indústrias que fazem uso intensivo dos fatores dos quais dispõem em abundância, exportando estes produtos e importando aqueles 
para os quais têm desvantagem comparativa de fatores. Assim, os países com mão-de-obra abundante e barata exportarão produtos que consomem muito trabalho. Por sua vez, as nações com grande disponibilidade de terra cultivável e condições edafoclimáticas favoráveis exportarão produtos que dependam da exploração econômica desses fatores.

Entre alguns autores contemporâneos tem crescido a convicção de que o argumento da vantagem comparativa baseada nos fatores de produção não seria suficiente para explicar os atuais padrões de competitividade. Para Porter (1990) a teoria padrão apresenta limitações, pois supõe que não há economias de escala, que as tecnologias são idênticas em toda a parte, que os produtos não são diferenciados e que o conjunto dos fatores nacionais é fixo.

Para Porter (1990) a competitividade de uma nação moderna estaria vinculada essencialmente ao conceito de conquistar e manter altos níveis de inovação e produtividade, e não à noção de explorar tradicionais vantagens comparativas; a mudança teria ocorrido em função dos processos de transformação tecnológica e globalização econômica. Tal conclusão, para ele entendida como condição sine qua non das novas regras normais do jogo do comércio internacional, mudaria completamente a percepção e interesse da concepção clássica de vantagem comparativa para vantagem competitiva.

No que pese o reconhecimento das limitações do arcabouço teórico ricardiano e da validade do conceito de vantagem competitiva, cumpre-nos efetuar uma ressalva às proposições de Porter (1990). Não se trata de desconhecer a contribuição trazida pelo conceito de vantagem competitiva construída, mas de alertar para a sua visão exclusivista. Embora a insuficiência da vantagem de fatores na explicação do comércio internacional seja geralmente reconhecida, está longe de ser claro o que deve substituí-la. Certamente que o acesso a fatores abundantes, em muitas indústrias, passou a ser menos importante que a tecnologia, diminuindo a vantagem de fatores, mas não anulando-a completamente. A dotação de fatores comparáveis ainda exerce a sua parcela considerável de influência no comércio internacional, especialmente em setores de commodities agrícolas.

Além de Porter (1990), outras críticas, em sentidos diferentes, apresentam-se ao referencial teórico neoclássico. Para Teixeira (1993) foi necessário o questionamento da teoria padrão, para que se pudesse incorporar no cerne da análise econômica o papel da tecnologia no processo competitivo. Herdeiros da tradição ricardiana, os economistas neoclássicos definem o conceito de competitividade a partir do modelo de competição perfeita. De acordo com esta abordagem, os estudos sobre competitividade devem enfocar, sobremodo, as causas do distanciamento entre o desempenho de um determinado setor daqueles parâmetros ótimos que são, teoricamente, possíveis de serem obtidos por meio da competição 
perfeita. Supõe a teoria padrão que todos os agentes econômicos têm acesso à informação e que o conhecimento tecnológico é acessível, codificável e perfeitamente transmissível.

Diante desta configuração, a existência de um aparato político-institucional que regule uma indústria é tomada como distorção das forças de mercado, bem como a tecnologia não é considerada como fator de diferenciação competitiva e instrumento de capacitação empresarial, mas entendida como acervo estático e conhecido. O questionamento do modelo teórico neoclássico implicou desatrelar o conceito de competitividade do referencial de competição perfeita e passar a associá-lo à noção de desempenho. Assim, a competitividade de uma determinada cadeia agroindustrial estaria relacionada, prioritariamente, à sua capacidade de formular estratégias competitivas que lhe permitam manter e ampliar a sua posição mercadológica, por meio de um esforço endógeno de geração e incorporação de inovações tecnológicas.

Neste sentido, a contribuição de Schumpeter (apud Teixeira, 1993) foi pioneira. Ao associar a base científica à base tecnológica de uma atividade, associação expressa na relação invenção-inovação, Schumpeter (apud Teixeira, 1993) fez com que a tecnologia fosse vista como um bem que incorpora certo sistema produtivo na sua criação, considerando custos e riscos. A partir daí, ciência e tecnologia que, pelos padrões da teoria neoclássica, se apresentavam como externas ao sistema econômico, se endogenizam como elemento primordial do processo de acumulação capitalista: a abordagem schumpeteriana rompe com o pressuposto neoclássico do mercado puro como força organizadora. Tal tentativa de abordagem dinâmica das estruturas de mercado conduziu à busca de modelos teóricos que internalizassem completamente o processo de inovação tecnológica de forma que captassem a sua capacidade de transformação das estruturas e dinamização do processo competitivo. Esta é a linha em que se desenvolvem os trabalhos de teóricos neoschumpeterianos, tais como Nelson e Winter (1982) e Dosi (1988).

Sobre a abordagem evolucionista de Nelson e Winter (1982), Possas (19--) identifica como argumento central a idéia de que as mudanças econômicas têm a sua origem na busca incessante, por parte das firmas, de introduzir inovações de processos e produtos com o objetivo de alcançar melhor posição no mercado, criando assimetrias. Tais inovações seriam submetidas aos mecanismos de seleção próprios da concorrência e do mercado. A interação endógena da estratégia da firma com a estrutura do mercado é então proposta como marco teórico alternativo para a abordagem dos processos de geração e difusão de inovações, vistos numa ótica evolucionista, por meio dos processos de busca e seleção de inovações. 
No que se refere à dimensão tecnológica das inovações, no seu caráter endógeno, Dosi (1988) propõe a transposição da noção de paradigma de Thomas Kuhn para o âmbito tecnológico, cunhando a expressão paradigmas tecnológicos, para representar os programas de pesquisa tecnológica baseados em modelos ou soluções de problemas tecnológicos selecionados, derivados de princípios científicos e tecnológicos igualmente selecionados e não genericamente abertos e exógenos, como supõe a teoria neoclássica.

Embora a competitividade industrial seja uma expressão muito difundida em análises e estudos, para Teixeira (1993) e Ferraz, Kupfer e Haguenauer (1996) estes ainda se ressentem da ausência de consenso quanto à definição do conceito e, por extensão, quanto às metodologias mais adequadas de avaliação. Para Ferraz, Kupfer e Haguenauer (1996) a maior parte desses estudos trata da competitividade como fenômeno diretamente relacionado às características de desempenho, apresentadas pelas empresas. Ponderado isso, eles definem a competitividade como a capacidade de a empresa formular e implementar estratégias concorrenciais, que lhe permitam ampliar ou conservar, de forma duradoura, uma posição sustentável no mercado.

Tal referencial baseia-se em três categorias de fatores de competitividade: empresariais, estruturais e sistêmicos. Enquanto os fatores empresariais são aqueles sobre os quais a empresa detém poder de decisão, os fatores estruturais, por sua vez, correspondem àqueles sobre os quais a capacidade de intervenção da empresa é limitada, estando por isto apenas parcialmente sob a sua influência. Finalmente, os fatores sistêmicos constituem externalidades stricto sensu, sobre as quais a empresa deteria escassa ou nenhuma possibilidade de intervir, como, por exemplo, o arcabouço político-institucional do seu ambiente de negócios. Deste modo, de acordo com a abordagem neoschumpeteriana de Ferraz, Kupfer e Haguenauer (1996), a competitividade decorre da capacitação acumulada pela firma, estando condicionada por fatores internos e externos a ela. Daí se infere que, na base da preservação das posições de mercado, está um contínuo processo de criação de vantagens competitivas, pressupondo vigoroso esforço endógeno de geração e incorporação de inovações (Loiola e Teixeira, 1994).

A despeito da propriedade e pertinência dos argumentos apresentados, observam-se, na abordagem neoschumpeteriana, as seguintes limitações: (1) a ênfase demasiada na internalização completa do processo de inovação tecnológica, por meio da interação das estratégias competitivas das empresas com a estrutura de mercado; (2) a concepção estruturalista das relações entre o Estado e os agentes econômicos como uma via de mão-única, com um só sentido de determinação: o Estado, interessado e autônomo, por meio de políticas públicas unilaterais, resultantes de uma intenção deliberada e planejada, provoca determinados com- 
portamentos na tomada de decisão de agentes privados; (3) a não consideração, nas relações entre a empresa e o Estado, da via de sentido oposto à abordagem estruturalista, isto é, a capacidade das estratégias empresariais de influenciar o processo de formação de políticas públicas.

Ao escolher uma abordagem que privilegia o progresso técnico e as formas de concorrência para explicar a incorporação de inovações tecnológicas e a consolidação de vantagens competitivas industriais, os neoschumpeterianos negligenciam a importância dos aspectos político-institucionais na análise da dinâmica desse processo, entre os quais vale a pena destacar a importância do intercâmbio político de influências, característico da relação de mão-dupla entre o Estado e as organizações de representação de interesses privados, na consolidação dos processos de geração de inovação tecnológica das empresas.

O estudo do fenômeno de emergência e consolidação do padrão de inovação tecnológica de clonagem do eucalipto no complexo agroindustrial de celulose, por exemplo, mostra a necessidade de articular as análise neoschumpeterianas com políticas públicas e auto-organização de interesses privados. Cumpre ressaltar que os aspectos técnico-econômicos não são os únicos a influenciar a dinâmica econômica das empresas e particularmente dos complexos agroindustriais.

\section{Configuração dos Complexos Agroindustriais: Padrão Neocorporatista de Relação entre o Estado e os Interesses Privados Auto-Organizados}

Para Soto (1992) e Graziano da Silva (1996) a proposição de um conceito operacionalizável de complexo agroindustrial, com base apenas nas relações internas de compra e venda entre determinados segmentos produtivamente articulados entre si, ou matriz insumo-produto ou encadeamento técnico-produtivo, aparece como indébita simplificação. Para eles, tais análises não incorporam a chamada dimensão político-institucional das cadeias produtivas, relacionada à existência de movimentos orquestrados pela ação de organizações de representação de interesses privados e autoridades governamentais. Essa dimensão permite tratar os complexos como resultado histórico de duplo movimento: de dentro, pela atuação das forças sociais, econômicas e políticas dos agentes que integram o complexo; de fora, pela ação do Estado por meio das políticas públicas e das suas agências, ao estabelecer relações particulares com os agentes anteriormente mencionados. 
Tais argumentos coincidem com as críticas feitas por Wilkinson (1996) à análise restrita das inovações tecnológicas no contexto das cadeias agroindustriais. A análise do ambiente institucional configura-se tão importante quanto a análise da inovação tecnológica. Wilkinson (1996) identifica entre esta nova literatura, que passa a lidar com a agroindústria, aquela que deixou de ser influenciada predominantemente pela onda de inovação tecnológica, orientando-se para um tipo de economia de inspiração neoinstitucional, capitaneada pelas proposições de North (apud Farina e Zylberstain, 1996), prêmio Nobel de economia em 1993.

Em linhas gerais, a principal contribuição dessa abordagem tem sido o estabelecimento das relações entre o ambiente político-institucional e o desenvolvimento econômico, nas quais as instituições são normas culturalmente construídas pelos seres humanos, incluindo as formas organizacionais, que funcionam como invólucro para as atividades econômicas, sociais ou políticas. Tais normas consistem tanto em restrições informais quanto formais, que estabelecem o espaço, onde são negociadas as regras do jogo, seja ele econômico, social, político, ou o próprio jogo institucional.

Uma das contribuições mais importantes do padrão neocorporatista, de inspiração neoinstitucionalista, é o tratamento dispensado às organizações de interesse privado. Os seus interesses são parcialmente conformados pelas variáveis setoriais; mas, ao mesmo tempo, também modelam e influenciam estas variáveis, no que Offe (apud Graziano da Silva, 1996) chama de "atribuição de status público aos grupos de interesse". Adicionalmente, o modelo neocorporatista não pode sobreviver sem a conivência ou cumplicidade do Estado, que é um dos atores sociais fundamentais do processo de concertação dos interesses envolvidos.

Dentro dessa nova concepção proporcionada pela abordagem neocorporatista situa-se a noção de complexo agroindustrial, como resultado histórico de uma aliança entre instituições públicas e privadas. Tal noção nos permite ver esses complexos enquanto verdadeiras máquinas de mediar interesses no quadro de relações, ora cooperativas, ora conflituosas, entre segmentos da iniciativa privada e o Estado, priorizando ou mesmo incluindo/excluindo atores que, por razões estritamente econômicas, deveriam ou não fazer parte de uma dada estrutura tecnoprodutiva. Ela nos propicia entender melhor o processo de elaboração e de implementação de políticas públicas específicas e da sua relação de mão-dupla com as estratégias empresariais, elementos centrais na explicação das dinâmicas particulares dos distintos complexos.

Assim, admite-se que a dinâmica das trocas econômicas e da geração e difusão de progresso técnico, no âmbito de determinado complexo produtivo, não pode ser compreendida por uma perspectiva que privilegie isoladamente, ora a ação monolítica de um Estado estruturalista, macroplanejador de políticas públi- 
cas, ora a ação dos grupos de pressão privados, por meio de lobbies, para influenciar autoridades públicas em seu favor, ora o papel das estratégias empresariais gestadas no interior das organizações, como elemento propulsor da competitividade e inovação tecnológica. Em síntese, ao agregar e articular a dimensão político-institucional à noção de complexo agroindustrial, abre-se nova agenda de investigação: compreender a dinâmica econômica dos processos de gestação e consolidação da inovação tecnológica, no interior dos complexos agroindustriais, como resultado de um processo histórico de concertação de interesses e negociação de acordos entre os seus atores sociais, atuando no seu espaço políticoinstitucional. Tal abordagem evidencia a ação do Estado e das organizações de interesses na explicação das suas dinâmicas diferenciadas. Mais que isto: os processos de decisão e os mecanismos de ação coletiva também passam a merecer lugar de destaque, assim como o papel das distintas organizações e instituições públicas e privadas.

\section{Aracruz Celulose S.A.: Perfil Corporativo}

A Aracruz Celulose S.A. é a maior produtora mundial de celulose de fibra curta de eucalipto, com uma capacidade de produção de 1.200.000 toneladas por ano, suprindo, aproximadamente, $22 \%$ da demanda mundial por celulose de eucalipto e cerca de 7\% por celulose de fibra curta (Citicorp, 1998). A empresa caracteriza-se por ser altamente intensiva em capital, fabricar uma commodity global e concorrer em um mercado cíclico (Aracruz Celulose, 1996). Uma das principais estratégias concorrenciais da empresa é a liderança de custo de produção apoiada principalmente pelo baixo custo de produção da madeira, obtida mediante a implantação de tecnologia florestal de ponta. O controle da Aracruz é exercido por quatro acionistas: o grupo norueguês Lorentzen (28\%), o sul-africano Mondi (28\%), o brasileiro Safra (28\%) e o Banco Nacional de Desenvolvimento Econômico e Social - BNDES (12,5\%). A empresa opera de forma integrada segundo um sistema baseado no trinômio florestas-fábricas-porto, ocupando uma área territorial de 203.000 ha e gerando cerca de 5.000 empregos diretos e indiretos (Aracruz Celulose, 1996). A base florestal da empresa espalha-se pelo norte do Espírito Santo (ES) e extremo sul da Bahia (BA), enquanto a fábrica e o porto estão situados no município de Aracruz (ES). 


\section{Articulação de Políticas Públicas e Auto-Organização de Interesses Privados: o Ambiente Politico-Institucional e o Padrão Eucalipto}

Entre 1960 e 1965, o Brasil tornou-se auto-suficiente no consumo de celulose, antes totalmente importada, e passou a fabricar papel com 100\% de celulose nacional, figurando o grupo empresarial Klabin, controlador de unidades de produção de papel a partir de celulose de fibra longa, como um dos principais atores deste processo, marcado pelo padrão corporatista tradicional de relação entre interesses públicos e privados, isto é, um sistema de representação de interesses privados tutelado pelo Estado, no qual as decisões empresariais são, em certa medida, provocadas pelas autoridades governamentais.

Nesse período, os desafios enfrentados para a modernização tecnológica e organizacional da indústria de papel e celulose e para a emergência do complexo agroindustrial de celulose de mercado, isto é, as empresas que não produzem papel e exportam celulose, eram: (1) a não integração floresta-indústria; (2) a seleção de espécies vegetais mais adequadas à fabricação de celulose; e (3) a elevação das economias de escala. Entre 1965 e 1980, o Programa de Incentivos Fiscais ao Florestamento e Reflorestamento (PIFFR) e a política de apoio ao desenvolvimento tecnológico, articulados com a política de financiamento subsidiado para o setor industrial do BNDES, contribuíram para a superação, com precisão cirúrgica, de todas as ameaças enfrentadas até então pelo complexo.

Segundo Mendonça Jorge (1992) e Carneiro (1993), a combinação de políticas públicas e a orquestração de interesses privados, no final da década de 60 , foi decisiva para a emergência e a consolidação do complexo agroindustrial brasileiro de celulose de mercado, baseado em fibra curta de eucalipto. Para estes autores, a consolidação do complexo agroindustrial brasileiro de celulose de mercado, pela viabilização de grandes projetos de celulose de fibra curta de eucalipto, a partir da segunda metade da década de 70, somente foi possível graças ao intercâmbio político que se realizou do Estado com a auto-organização de interesses privados, que transformou os desafios identificados, no final da década de 60 , em oportunidades que levaram ao salto qualitativo e quantitativo da indústria de papel e celulose.

Entre 1964 e 1974, a Associação Nacional de Fabricantes de Papel e Celulose (ANFPC) assumiu o monopólio da representação da totalidadade dos interesses da indústria brasileira de papel e celulose, sendo reconhecida e legitimada pelo Estado como o interlocutor no processo de negociação de políticas públicas. Para isto, a ANFPC exerceu uma orquestração entre interesses privados com o obje- 
tivo de moldar e subordinar, em certa medida, os interesses empresariais individuais a um interesse de caráter coletivo, o interesse da organização que os representa num espaço, onde se realiza a interação dos interesses públicos e privados (Soto, 1992).

Assim, em um contexto político-institucional específico, as políticas públicas de desenvolvimento científico e tecnológico, direcionadas para a configuração do padrão eucalipto e conjugadas com interesses empresariais auto-organizados, exerceram um papel fundamental para a competitividade alcançada, a partir da década de 80 , pelo complexo agroindustrial de celulose de mercado.

\section{Políticas Públicas de C\&T e Padrão Eucalipto}

A necessidade de constituição de uma base florestal para o abastecimento da indústria, os elevados riscos e investimentos, associados aos programas de $\mathrm{P} \& \mathrm{D}$ para seleção e adaptação de espécies de eucalipto mais adequadas para a produção de celulose, fizeram com que todo o esforço de pesquisa florestal, nos anos 70 , ficasse concentrado em institutos públicos de pesquisa florestal. O financiamento dessas pesquisas era proveniente do Instituto Brasileiro de Desenvolvimento Florestal (IBDF), que destinava $1 \%$ do volume total de recursos envolvidos no âmbito do PIFFR para estimular o surgimento de grupos de pesquisa florestal que atendessem as demandas específicas das empresas privadas.

Em 1968, por iniciativa conjunta da Escola Superior de Agricultura Luiz de Queiroz (ESALQ-USP) e empresas privadas do setor de papel e celulose (Champion, Duratex, Rigesa, Suzano e Madeirit), foi criado o Instituto de Pesquisas e Estudos Florestais (IPEF), contando com financiamento público, vindo dos incentivos fiscais ao reflorestamento. De acordo com Soto (1992), o IPEF, cujo objetivo é gerar e difundir o desenvolvimento científico e tecnológico do setor florestal por meio da integração empresa-universidade, foi o principal responsável pela pesquisa florestal no país até meados da década de 70. Em 1979, a implementação, em escala industrial, da tecnologia de clonagem do eucalipto pela Aracruz Celulose S. A., contou com o apoio do IPEF, que vinha, desde 1973, trabalhando em pesquisas na área de melhoramento genético do eucalipto.

Em 1974, as empresas privadas passaram a contar com outro apoio institucional para a pesquisa florestal. Neste ano foi criada a Sociedade de Investigações Florestais (SIF), ligada ao Departamento de Engenharia Florestal da Universidade Federal de Viçosa (UFV), com o mesmo objetivo do IPEF: promover a pesquisa florestal mediante a integração empresa-universidade na elaboração de projetos cooperativos relacionados a problemas técnico-econômicos da indústria florestal brasileira. 
Como as condições tecnológicas para a produção de celulose de fibra curta de eucalipto, em larga escala, ainda não estavam totalmente equacionadas até o final dos anos 60 , a socialização das incertezas tecnológicas e financeiras, mediante $\mathrm{o}$ apoio das políticas públicas do IBDF e BNDES, foi essencial para a construção e a consolidação, nos anos 80 , de vantagens competitivas pelo complexo agroindustrial de celulose. Assim, o desenvolvimento tecnológico do padrão eucalipto somente foi possível graças a uma marcante articulação entre Estado e iniciativa privada. Sem desconhecer a importância decisiva dos fatores técnicos, podemos afirmar que as políticas públicas de desenvolvimento científico-tecnológico induziram, significativamente, o processo de inovação tecnológica assentado na clonagem do eucalipto. Sem a consideração dessas políticas, a interpretação do processo tecnológico que resultou na consolidação do padrão eucalipto no complexo agroindustrial brasileiro de celulose seria, no mínimo, incompleta.

O projeto da Aracruz Celulose S. A. foi emblemático, neste sentido, pois do seu êxito dependia a consolidação, nos anos 80 , deste novo paradigma econômicotecnológico para o complexo agroindustrial de celulose de mercado. Chamado, por Mendonça Jorge (1992), inspirado em Nelson e Winter (1982) e Dosi (1988), de padrão eucalipto, este novo paradigma tem como principais características: (1) o uso do eucalipto como matéria-prima predominante para a produção de celulose de fibra curta; (2) a escala ótima de produção de 1.000 t/dia de celulose; (3) a dependência de instrumentos externos de financiamento, a longo prazo, para os investimentos e participação acionária do Sistema BNDES.

Assim, segundo Soto (1992), a consolidação de um novo paradigma econômico-tecnológico no complexo agroindustrial brasileiro de celulose, aqui denominado padrão eucalipto, pode ser interpretada como, em boa medida, o resultado histórico de um processo de acordo de interesses entre as organizações de representação de interesses privados, particularmente a ANFPC, e as agências governamentais, em particular o BNDES e o IBDF.

O intercâmbio político existente na relação neocorporatista desses interesses privados com o Estado, envolvia um processo de duplo sentido: se, por um lado, a representação dos interesses privados procurava influenciar as autoridades do governo com o propósito de provocar decisões que a favorecessem (por exemplo, as barreiras à entrada que os grupos empresariais não conseguiam levantar no âmbito da concorrência, eram solicitadas ao Estado, via mecanismos institucionais), por outro lado, as autoridades governamentais, usando como trunfo a proteção institucional dada, procuravam influenciar a articulação dos interesses privados e contar com a participação da ANFPC na execução de determinadas políticas públicas. Assim, ambos os sentidos convergiram para a configuração de um processo de gestão de políticas públicas com uma lógica comum: a 
consolidação, em bases competitivas, de um novo complexo agroindustrial de celulose, assentado no padrão eucalipto.

\section{Aracruz e Padrão Eucalipto: Estratégia Tecnológica Ambiente Institucional}

Segundo Mendonça Jorge (1992), a Aracruz desempenhou importante papel na consolidação da utilização do eucalipto como fonte de material fibroso para a fabricação de celulose. Conforme Beckel (1995), os principais determinantes para isto foram os solos pouco férteis e empobrecidos pelo fim do ciclo cafeeiro, a falta de experiência com relação à plantações de eucalipto na região norte do Espírito Santo (ES) e a carência de material genético de eucalipto adaptado às condições locais. Essa situação crítica, responsável por uma produtividade florestal inicial insignificante, impulsionou uma estratégia tecnológica ativa da empresa para o fomento à pesquisa florestal, visando ao aumento significativo de produtividade. A impossibilidade de comprar as espécies desejadas no mercado induziu um processo de capacitação tecnológica na área florestal, pela estratégia de cooperação tecnológica entre o Centro de Pesquisa e Tecnologia da Aracruz (CPT) e institutos públicos de pesquisa florestal.

\section{Cooperação Tecnológica: a Relação Aracruz-Instituições Públicas de Pesquisa}

Criado em 1973, o CPT é resultante do antigo Centro de Pesquisa Florestal da Aracruz (CEPAR), vinculado à subsidiária Aracruz Florestal S/A, extinta em 1993. O CPT é a consolidação do esforço de pesquisa florestal da Aracruz em face do desafio de aumentar a produtividade das primeiras plantações de eucalipto e selecionar as espécies mais adequadas às condições edafoclimáticas existentes. Atualmente, o centro conta com três gerências: Tecnologia (gerência corporativa), Melhoramento de Florestas Plantadas (tecnologia florestal) e Desenvolvimento de Produtos (tecnologia industrial), e cerca de 62 funcionários, sendo 10 pesquisadores pós-graduados (Bertolucci, 2000).

O investimento total anual em $\mathrm{P} \& \mathrm{D}$, em média, equivale a $0,5-1,0 \%$ do faturamento bruto da Aracruz Celulose S. A., a depender do preço da celulose no mercado internacional. Deste montante, cerca de $60 \%$ é destinado à pesquisa florestal e 40\% à industrial (Sharland, 1996; Bertolucci, 2000). Coerente com a estratégia competitiva de base tecnológica da Aracruz de buscar sempre posicionar-se no estado da arte da tecnologia para a produção de celulose de fibra curta de eucalipto, por meio da liderança da tecnologia florestal e do acompanhamento rápido da tecnologia industrial, o CPT tem como objetivos 
principais aumentar a qualidade e a quantidade de madeira proveniente das plantações de eucalipto e oferecer serviços técnicos diferenciados aos clientes (Aracruz Celulose, 1996, 1997).

Com o objetivo de complementar os seus recursos próprios durante o período correspondente ao processo de desenvolvimento tecnológico florestal, a Aracruz buscou base científica e orientação tecnológica, principalmente de pesquisa básica, em instituições científico-tecnológicas de caráter público, nacionais e internacionais, com as quais a empresa ainda mantém intercâmbio permanente e colabora prestando o seu apoio logístico para cursos de extensão, dissertações de mestrado e teses de doutorado.

Segundo Aracruz Celulose (1997) e Bertolucci (2000), atualmente o CPT mantém parcerias de intercâmbio científico-tecnológico com universidades nacionais e internacionais, institutos de pesquisa, fabricantes de papel e celulose e clientes, tais como: USP/ESALQ/IPEF, UFV/SIF, EMBRAPA, IPT, Oregon State University, Michigan Technological University, Consórcio da Universidade de Toronto, International Union of Forestry Research Organizations (IUFRO), Empire State Paper Research Associates (ESPRA), Associação Brasileira de Obtentores Vegetais (BRASPOV), Fundação de Apoio ao Ensino, Pesquisa e Extensão da Universidade Federal de Lavras (FAEPE) etc.

\section{Do Melhoramento Genético de Sementes à Tecnologia de Clonagem}

O programa de desenvolvimento tecnológico da Aracruz teve seu início em 1973. Este programa começou com um projeto de melhoramento genético do eucalipto, mediante a introdução e avaliação de 55 espécies de eucalipto originárias da Austrália e da Indonésia. As sementes das variedades selecionadas se reproduziam em viveiros especialmente implantados com este propósito. O objetivo era aumentar a produtividade por meio de um programa de inovação tecnológica de longo prazo, adaptado às condições dos ecossistemas locais e à produção de celulose. Como resultado desse primeiro esforço tecnológico, a Aracruz passou a produzir sementes híbridas, em grande escala, a partir de cruzamentos de Eucalyptus Grandis com Eucalyptus Urophylla, as espécies de maior rendimento entre as 55 avaliadas.

Dado que já se sabia das dificuldades do cultivo tradicional por meio de sementes (longo período para a produção de árvores geneticamente superiores de eucalipto, irregularidade da matéria prima obtida nas plantações quanto ao diâmetro, altura, qualidade da madeira etc), a Aracruz diversificou a sua estratégia de pesquisa florestal aplicada de melhoramento genético, por meio do desenvolvi- 
mento da técnica de propagação vegetativa por estacas. Esta foi a via alternativa que a empresa encontrou para tentar diminuir o ciclo de melhoramento tradicional do eucalipto de aproximadamente 12 anos, através de sementes, para cerca de 5 anos, utilizando-se do processo de clonagem.

O método de propagação vegetativa consistia em identificar árvores superiores nas plantações de eucalipto para logo reproduzí-las, em larga escala, por meio de clonagem. Ao invés de sementes, esta técnica utiliza parte da planta (estaca) para a propagação. A tecnologia de clonagem permitiria conservar todo o potencial genético da árvore-mãe, selecionada pelas suas ótimas características florestais e industriais, assegurando o aumento da eficiência do processo industrial e da qualidade da celulose (Gertner et al., 1997).

Em 1975, ao observar que existiam árvores muito superiores nas suas plantações iniciais de eucalipto, a Aracruz optou pela estratégia de produzir bosques industriais a partir da propagação vegetativa de clones destas árvores. Assim, a empresa iniciou os estudos para aperfeiçoar, para a escala industrial, o método de propagação vegetativa, mediante o enraizamento de estacas, existente em outros países somente em escala experimental. A partir de 1979, a Aracruz implantou, em larga escala, florestas clonais de elevada produtividade, quando comparadas com as obtidas por sementes. Em 1986, os resultados tecnológicos obtidos com as plantações clonais, após o primeiro ciclo de corte, corroboraram as expectativas geradas pela pesquisa florestal. Além de maior rendimento florestal de madeira, o consumo específico de madeira por tonelada de celulose (rendimento industrial) reduziu-se, entre 1986 e 1994, de 4,60 para 3,85 $\mathrm{m}^{3}$, com aumento significativo da produção de celulose por unidade de área plantada de eucalipto (Gertner et al., 1997). Esses esforços de desenvolvimento tecnológico resultaram em plantações de eucalipto que permitem a fabricação de celulose de forma competitiva e rentável, fazendo com que a produtividade florestal da Aracruz quase duplicasse em 7 anos: de $25 \mathrm{~m}^{3}$, em 1987, para $45 \mathrm{~m}^{3}$ de madeira de eucalipto por hectare/ano, em 1994 (Aracruz Celulose, 1997).

$\mathrm{O}$ aumento de produtividade florestal, resultado do processo de desenvolvimento tecnológico baseado na clonagem do eucalipto, permitiu a construção de novas fronteiras competitivas para a Aracruz, que detém as plantações de eucalipto mais produtivas do mundo. Os ciclos de corte da madeira do eucalipto tempo de maturação do plantio da muda ao corte da árvore - variam muito de uma região para outra, dependendo do solo, das condições climáticas e do tipo de florestas. As florestas tropicais são mais produtivas do que as florestas das tradicionais regiões produtoras da Europa e da América do Norte. Para o eucalipto, o ciclo de corte na Aracruz (ES) é somente de 7 anos, e de 12-15 anos na Península Ibérica; para outras espécies, também utilizadas na produção de celu- 
lose de fibra curta, como a bétula, o ciclo de corte na Escandinávia situa-se entre 35-40 anos (Swirski e Tanaka, 1996).

Isto torna possível, por exemplo, a implantação, no norte do Espírito Santo ou no extremo sul da Bahia, de uma fábrica com capacidade de 500.000 toneladas de celulose/ano, utilizando-se uma base florestal de apenas 73.000 hectares de eucalipto. Essa mesma fábrica necessitaria de uma floresta de 800.000 hectares de bétula na Finlândia ou de 1.600.000 de hectares de florestas de coníferas no leste canadense (Carneiro, 1993; Aracruz Celulose, 1999).

\section{Conclusóes}

Partindo do pressuposto de que o processo de inovação tecnológica na Aracruz Celulose S.A., além do esforço endógeno de construção de estratégias empresariais, tenha sido fruto de um duplo movimento de articulação de políticas públicas e auto-organização de interesses privados, resolvemos complementar a concepção teórica neoschumpeteriana utilizada com a abordagem institucionalista.

Tal relacionamento entre os interesses privados e o Estado foi analisado à luz das contribuições dos autores da linha neocorporatista, segundo os quais a estrutura e a dinâmica, até mesmo a inovação tecnológica, das cadeias produtivas são, em boa medida, o resultado histórico de um processo de mediação de interesses de duas vias, entre grupos privados organizados e as agências governamentais, para a construção de acordos sucessivos de ganha-ganha, que convergem para uma forma particular de gestão de políticas públicas: se, por um lado, o Estado, entre as décadas de 60 e 80, com o planejamento de políticas públicas, contribuiu de forma seminal como agente indutor do processo de inovação tecnológica, que resultou na configuração do padrão eucalipto nas estruturas de mercado e formas de concorrência do complexo agoindustrial de celulose, as organizações de interesse privado, por seu turno, exercendo uma verdadeira orquestração dos interesses empresariais, não só influenciaram a gestão das políticas públicas, como chegaram a condicionar a autonomia de decisão dos agentes econômicos dos distintos segmentos que compõem o complexo agroindustrial brasileiro de papel e celulose.

Dentro dessa abordagem integrada e articulada de análise de dinâmica competitiva, podemos argumentar que a configuração do complexo agroindustrial de celulose foi resultado histórico da interação entre as estratégias concorrenciais empresariais e o aparato político-institucional. Tal aparato foi construído mediante a orquestração consciente de interesses, desenvolvida dentro de um pa- 
drão neocorporatista de relacionamento Estado-organizações de representação de interesses privados. Ao construir este argumento, chegamos a algumas constatações que nos permitiram extrair lições para futuras investigações relativas ao estudo da dinâmica econômica de complexos agroindustriais como vêm discriminadas a seguir.

. A insuficiência da grade de análise que privilegia o progresso tecnológico neoschumpeteriano na explicação da dinâmica do complexo agroindustrial de celulose. Sem desprezar o papel da inovação tecnológica, fruto de estratégias concorrenciais que buscavam uma posição assimétrica no mercado, ele é insuficiente para explicar a dinâmica econômica do complexo.

A validade do conceito ricardiano de vantagens comparativas como um dos indicadores da dinâmica competitiva do complexo agroindustrial de celulose. Não se trata de negar as restrições deste referencial teórico, de matiz neoclássico, nem tampouco de desconhecer a contribuição trazida pelo conceito de vantagem competitiva construída, mas de alertar para a sua visão exclusivista. A dinâmica competitiva da Aracruz chama atenção para um esforço de construção de vantagens competitivas, de base tecnológica, que sustentem as vantagens comparativas dadas pelas excelentes condições edafoclimáticas da região norte do Espírito Santo e do extremo sul da Bahia, para o plantio de eucalipto.

As limitações da abordagem teórica que privilegia exclusivamente o papel do Estado estruturalista, no qual as políticas públicas são o resultado exclusivo de uma intenção deliberada, monolítica e/ou de uma ação de planejamento das agências governamentais. Nessa perspectiva, as relações entre o Estado e a auto-organização dos interesses privados são de mão única. Este padrão de relacionamento é insuficiente para explicar a dinâmica do complexo agroindustrial de celulose que foi socialmente construída, entre as décadas de 70 e 80 , graças à articulação e combinação entre arranjos organizativos de interesses privados e políticas públicas, num padrão neocorporatista de relação de mão dupla.

A importância da incorporação efetiva das políticas públicas e do intercâmbio político neocorporatista de agências governamentais com organizações de representação de interesses privados no estudo da dinâmica do complexo agroindustrial de celulose, com o objetivo de buscar uma interpretação mais abrangente, integrada e articulada dos processos de inovação tecnológica e construção de vantagens competitivas. 
Referéncias Bibliográficas

ARACRUZ CELULOSE.

Apresentação à rede Tribuna de Comunicação. Espírito Santo, 1996 .

Our company. [online] Disponível na Internet via WWW.URL : http:// www.aracruz.com.br. 1997.

Apresentação sobre a Aracruz Celulose S.A. com enfâse nas operações florestais na Bahia. Bahia, set. 1999.

\section{BECKEL, J.}

Aracruz Celulose : aplicación de las ciencias biológicas al desarrollo de plantaciones florestales y la gestión sustentable del territorio. In: Innovación en tecnologías y sistemas de gestión ambientales en empresas líderes latinoamericanas. Santiago do Chile : CEPAL/ONUDI, 1995. p. 161177.

BERTOLUCCI, F. DE L. G.

Informações sobre inovação tecnológica de clonagem do eucalipto. [S.1. : s.n.], 2000.

CARNEIRO, R. A. F.

A competitividade como resultado da atuação estatal, das estratégias empresariais e da inovação : aplicação teórica à indústria de papel e celulose. Salvador, 1993. Dissertação (Mestrado em Administração) - Escola de Administração, Universidade Federal da Bahia.

\section{CITICORP SECURITIES.}

Brazilian pulp and paper industry : Aracruz Celulose S.A. New York, July 1998. p. 34-42

DAY, R.;

KRUGLIANSKAS, I.;

AZEVEDO, T. R.

Aracruz Celulose S.A. and Riocell S.A.: efficiency and sustainability on Brazilian pulp plantations. In: THE SUSTAINABLE FORESTRY WORKING GROUP (Ed.). The business of sustainable forestry : case studies. [S.1. : s.n.], 1998. p. 5-1/ 5-31.

DOSI, G.

The nature of the innovative process. London : Pinter, 1988.

FARINA, E.;

ZYLBERSTAIN, D.

Competitividade e organização das cadeias agroindustriais. In: MACHADO FILHO, C. et al. Agribusiness europeu. São Paulo : Pioneira, 1996. 
FERRAZ, J. C.;

KUPFER, D.;

HAGUENAUER, L.

Made in Brazil : desafios competitivos para a indústria. Rio de Janeiro : Campus, 1996.

GERTNER, D. et al.

Aracruz Celulose. In: WARD, S.; PRATT, L. (Eds.). La empresa sostenible en América Latina: estudios de caso. Washington, DC: World Resources Institute, 1997. p. 117-146.

GRAZIANO DA SILVA, J.

Complexos agroindustriais e outros complexos. In: A nova dinâmica da agricultura brasileira. Campinas : UNICAMP, 1996.

\section{KENNY, J.}

Market pulp : capacity grows, but market pulp output stagnates. In: Pulp\&Paper International. New York: Miller Freeman, 1997. p. 49-51.

\section{LOIOLA, E.;}

\section{TEIXEIRA, F.}

Agroindústria, competitividade e política regional. Revista de Administração Pública, v. 30, n. 1, jan./fev. 1994.

MACEDO, A. R. P.;

MATTOS, R. L. G.

A trajetória de crescimento dos principais produtores brasileiros de papel e celulose - 1970/94. BNDES Setorial, n. 3, p. 49-79, mar. 1996.

MACHADO FILHO, C. et al.

Agribusiness europeu. São Paulo : Pioneira, 1996.

MACHADO, R. T. M.

Fundamentos sobre o estudo da dinâmica das inovações no agribusiness. Revista de A d $\mathbf{m}$ i $n$ i s t $\mathbf{r}$ a ç $\tilde{a}$ o Contemporânea, v. 2, n. 2, p.127-141, maio/ago. 1998.

MALASSIS, L.

Vida rural e mudança social. São Paulo : Companhia Editora Nacional, 1973.

MENDONÇA JORGE, M. O.

Emergência e consolidação do "padrão eucalipto" na Indústria Brasileira de Celulose de Mercado. Campinas, 1992. Dissertação (Mestrado em Economia) - Instituto de Economia, Universidade Estadual de Campinas.

NELSON, R.;

WINTER, S.

An evolutionary theory of economic change. Cambridge : The Beknap Press, 1982.

PORTER, M.

A vantagem competitiva das nações. Rio de Janeiro : Campus, 1990. 
POSSAS, M.

Em direção a um paradigma microdinâmico : a abordagem neoschumpeteriana. [S.1.], [s.n.], [19--]. mimeo.

POSSAS, M.;

SALLES FILHO, S.;

SILVEIRA, J. M.

An evolutionary approach to technological innovation in agriculture : some preliminary remarks. Cadernos de Ciência e Tecnologia, v. 11, n. 1, 1994.

SHARLAND, E. M. R.

Gestão ambiental : transformações sofridas frente às exigências do mercado. In: Concurso Nacional de "Case Studies" Mário Henrique Simonsen. Rio de Janeiro : FGV, 1996. p. 221-240.

SOTO, F.

Da indústria do papel ao complexo florestal no Brasil : o ca- minho do corporatismo tradicional ao neocorporatismo. Campinas, 1992. Tese (Doutorado em Economia) - Instituto de Economia, Universidade Estadual de Campinas.

SWIRSKI, M.;

TANAKA, C.

Aracruz Celulose S.A. : construindo uma nova fronteira competitiva. In: Concurso Nacional de "Case Studies" Mário Henrique Simonsen. Rio de Janeiro : FGV, 1996. p. 35-46.

TEIXEIRA, F.

Breve referencial teórico. Salvador, NPGA/UFBA, 1993. mimeo.

\section{WILKINSON, J.}

A inovação organizacional é tão importante quanto a tecnológica. OPS, v. 1, n. 1, 1996. 